\title{
Computer-Based Teaching of Lexis in Primary School
}

\author{
Julia Pirverdieva, Karina Neganova, and Nonna Pelevina
}

NCFU, Department of Linguistic and Lingvodidactics, Stavropol region, Stavropol, Pushkin Street 1, Russia

\begin{abstract}
The article deals with the use of modern computer technologies in the lexical skills formation in primary school students at the foreign language lessons. The work describes the author's computer-based methods, which include a developed website with a various list of exercises and tasks at the stage of using vocabulary (variant-situational stage): exercises for controlling of vocabulary (correlate words with translation, connect pairs of synonyms or antonyms, and find a definition of a foreign word), thematic crosswords and interactive testing. Also within the framework of the website, we developed a descriptive electronic dictionary with hyperlinks to the context. Various children's fairy tales were offered as contexts in English. In order to confirm the research hypothesis, an experiment was conducted. The results of the experiment allowed the authors to justify the use of modern ICT at foreign language lessons in order to increase the level of lexical skills of primary school students.
\end{abstract}

\section{Introduction}

The rapid development of the information society, the wide spread of electronic information resources, multimedia and network technologies, create prerequisites for the implementation of a new integrated concept in modern education, the main principle of which is the implementation of ICT for personal development of all participants in the educational process: students, teachers, parents. In this regard, the issue of the formation of foreign competence among primary school students becomes relevant in primary school. At the same time, the efficiency of lexical skills formation at an early stage of training largely depends on the use of modern information and communication technologies, which helps to optimize the learning process and its transition to a qualitatively new level of development.

The application of ICT within the framework of the "Foreign Language" discipline provides great opportunities for increasing the effectiveness of teaching foreign-language communication. This is evidenced by many works of scientists in the field of teaching foreign languages methods (N.Yu. Aleksandrova, I.V. Alekhin, T.V. Bagaeva, V.P. Bespalko, MGBondarev, B.S. Gershunsky, A.V. Zhozhikov, and others). The analysis of these works showed that ICTs can not only accelerate the formation of speech skills and immerse students in the context of foreign culture, but also contribute to the optimization of independent work in the process of foreign language learning.

However, only a few works on the basis of ICT have been devoted to certain aspects of the junior schoolchild's lexical skills formation (T.V. Bagaeva, E.V. Solopova, L.A. Tsvetkova). In addition, many scientists (M.Z. Biboletova, I.L. Bim, T. Grafova, O.V. Danilenko, and others) note less active introduction of computer technologies in the process of foreign language teaching in a modern school at the initial stage. This is due to the shortage of quality software for primary school students and, possibly, of the lack of a unified approach to the development of electronic textbooks. Such a discrepancy in the process of teaching to the needs of children to learn a foreign language, with orientation to the mastery of knowledge only, and not to communicative competence formation that can allow to speak another language, make us to talk about a number of contradictions that exist in the system of teaching younger students a foreign language. Consequently, our research, whose goal is the junior schoolchild's lexical skills formation through the use of modern information and communication technologies, is becoming relevant.

\section{Materials and methods}

In the context of the problem, we are researching, we will consider the concept of lexical skill. According to the dictionary of methodological terms of E.G. Azimova and A.N. Shchukin, the term is understood as an automated action on the choice of a lexical unit which is adequate to the intent and in accordance with the norms of combination with other units in productive speech, as well as automated perception and association with meaning in receptive speech [1]. 
A lexical skill is the ability to perform automatically and independently a series of actions and operations connected with instantly calling the standard of a word from a long-term memory and correlating it with another lexical unit, as well as its inclusion in the speech chain (L.A. Tsvetkova, N.D. Galskovoy).

Informational technologies, actively using the practical and methodical aspects of the pedagogical sphere, make the process of learning new vocabulary with the use of ICT more effective if conditions for using computer technology are created at the lesson of a foreign language, there is a stimulation of learning new vocabulary through ICT and developing computer skills and the Internet network [8].

Due to the fact that today a large number of native and foreign educational programs are used in practice, a number of methodological and didactic tasks are solved in English lessons with the help of a computer.

However, the review and comparative analysis of modern computer programs have shown that exercises predominate in them can be used at the orientingpreparatory (acquaintance with the new material) and situational-stereotyping (primary fixation), and only a few - at the variational-situational stages (development of skills and habits of using vocabulary) (N.D. Gal'skova, N.I. Gez).

In this regard, in the master's dissertation, we developed the methods aimed at primary school students' formation of the lexical skills at a variatively-situational stage through the use of modern ICT. These techniques are presented by the website with an expanded list of exercises and tasks at the stage of development of skills and abilities to use vocabulary.

The specific goal of the developed methods is to assist teachers in carrying out work on the formation of lexical skills in junior schoolchildren at the stage of using vocabulary (a variant-situational stage).

The website with the implemented methods:

- is aimed at the students of the junior school in order to consolidate and develop their skills and abilities to use the vocabulary in the lessons of systematization, generalization and consolidation of lexical material;
- is developed taking into account the main general didactic principles: activity, accessibility and visibility (the interface of the site is as available as it is accompanied by comments and tips).

The methods developed by us include the following exercises on topics Food and Drinks, Animals, Family, School items, Toys, Clothes:

1. Vocabulary lexicon for the self-analysis (for example, matching words to translations, establishment a pair of synonyms or antonyms, giving the classification of the words related to the same topic in Mind map and others).

Here is an example of such type of exercise: Classify the words below in the scheme (Figure 1), starting from the thematic principle (Mind map method): doll, apple, cap, lorry, sister, teddy bear, skirt, puppet, duck, kite, sheep, toy soldier, tomato, ball, bricks.

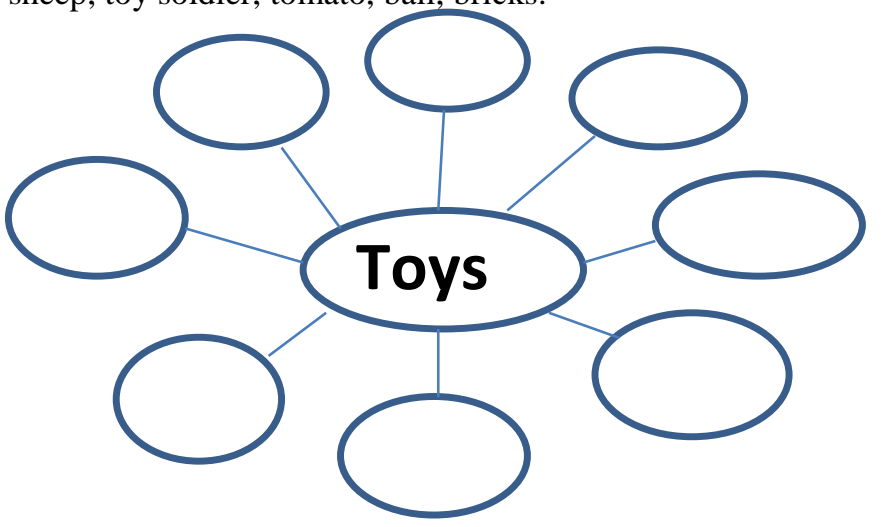

Fig. 1. Exercise for self-control on the topic "Toys" (Mind map).

2. Thematic crosswords. The peculiarity of such crossword is the correlation of the words contained in it with one topic. The thematic crossword puzzles are designed taking into account the feedback, which is as follows: if the student enters the word incorrectly, then the program signals an error, so if the crossword is filled correctly (Figure 2), the word "Perfect!" (Молодец) will be displayed. If there are mistakes, the system will display "Think again!" 


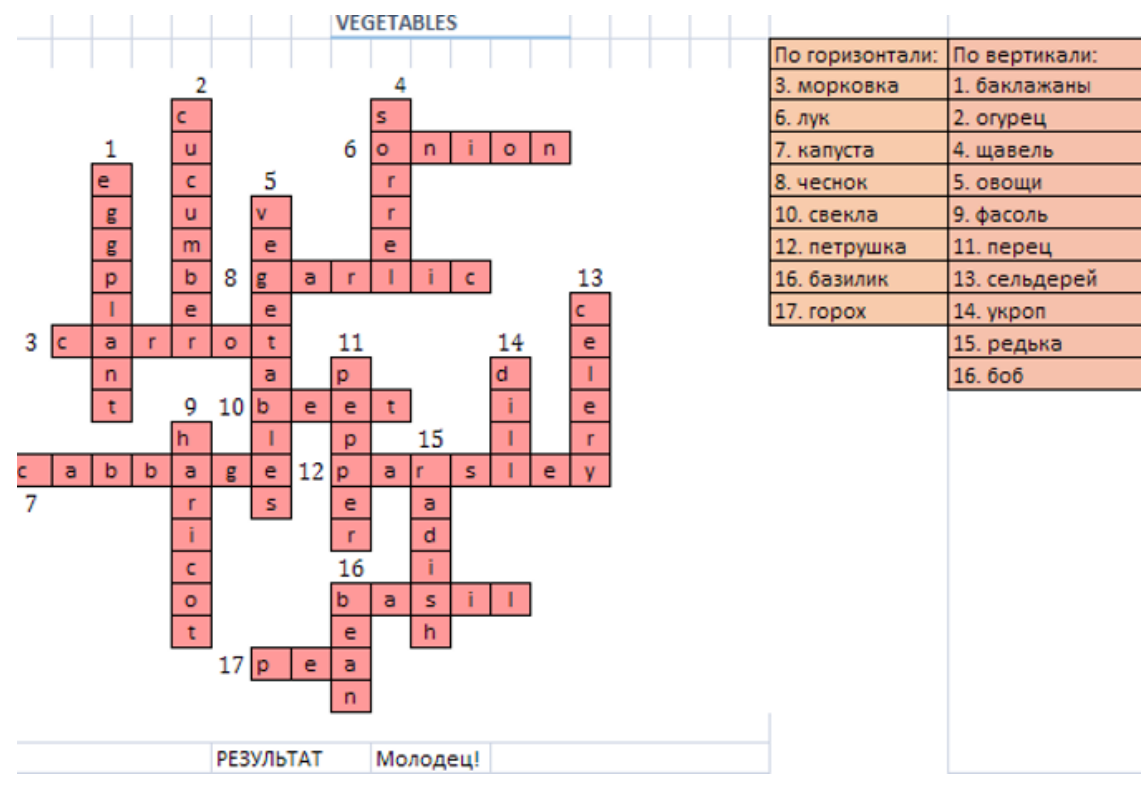

Fig. 2. Thematic crossword "Vegetables".

The developed thematic crosswords also have different levels of complexity, for example, the crosswords in which tasks are given in English (figure 3).

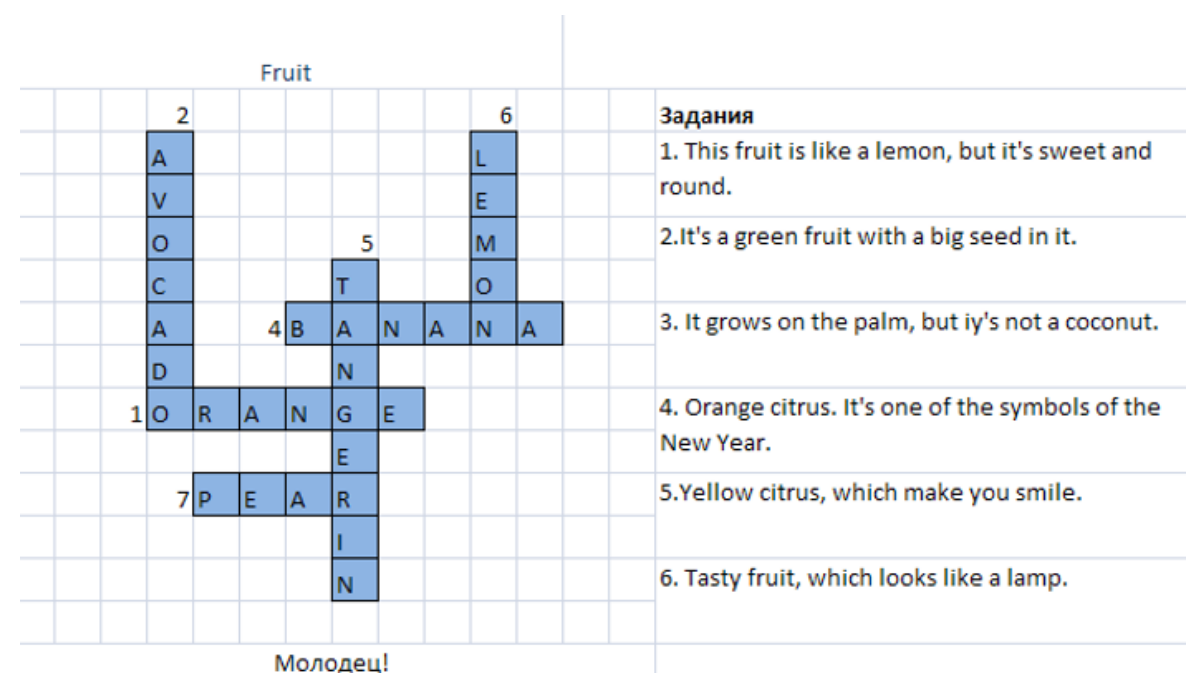

Fig. 3. Thematic crossword "Fruit".

3. Interactive testing. There are questions and a selective version of the answer - the listener is offered a list of answers from which he chooses the right answer in the compiled computer tests (Figure 4). 


\begin{tabular}{|c|c|c|c|c|}
\hline & Задание & Ответ & & Фио \\
\hline 1 & $\begin{array}{l}\text { My favourite clothes in summer is ___ and jeans. } \\
\text { 1.T-shirt } \\
\text { 2.P-shirt } \\
\text { 3.D-shirt }\end{array}$ & 1 & & Класс \\
\hline 2 & $\begin{array}{l}\text { Слово "skirt" переводится } \\
\text { 1.Рубэшкя } \\
\text { 2. Юбкя } \\
\text { 3. Брюки }\end{array}$ & 2 & & \\
\hline 3 & $\begin{array}{l}\text { Слово "пальто" переводится } \\
\text { 1.Shirt } \\
\text { 2.Cogt } \\
\text { 3.Jadket }\end{array}$ & 2 & & \\
\hline 4 & $\begin{array}{l}\text { Sometimes men in Scotland wear } \\
\text { 1. Skirts } \\
\text { 2. Blouses } \\
\text { 3.Belts }\end{array}$ & 1 & & \\
\hline 5 & $\begin{array}{l}\text { In rainy weather I usually wear a } \\
\text { 1. Rain-shirt } \\
\text { 2. Rain-jadket. } \\
\text { 3.Rain-cost }\end{array}$ & 3 & & \\
\hline 6 & $\begin{array}{l}\text { When it is cold, I sleep in } \\
\text { 1. Skirt } \\
\text { 2.Shorts } \\
\text { 3.pyjamas }\end{array}$ & 3 & $\nabla$ & \\
\hline 7 & $\begin{array}{l}\text { What kind of clothes do we put on in winter? } \\
\text { 1.Rain-cost and umbrella } \\
\text { 2. T-shirt and shorts } \\
\text { 3.Jadket and scarf }\end{array}$ & & & \\
\hline
\end{tabular}

Fig. 4. Interactive test on the topic "Clothes".

To summarize the results of testing, a hyperlink to another page of the site is provided, on which the number of correct and incorrect answers will be given and an estimate will be determined. The developed tests also have a different level of complexity.

4. Electronic dictionary. This dictionary with hyperlinks is designed to illustrate the use of lexicon in context. As a context, various fairy tales are offered in English ("Cinderella", "Little Red Riding Hood", etc.).
The dictionary is also based on a thematic principle and includes a list of topics mentioned above.

Here is an example of using an electronic dictionary: The topic "Family" includes such words as mother, father, sister, brother, daughter, son, grandfather, grandmother, step-mother, aunt, uncle, Godmother, stepdaughter. In the topic "Clothes": clothes, skirt, shoes, hat, trousers, shirt. In the following Cinderella fairy tale fragment (Figure 5), we see the highlighted words in these topics, where students can go through the hyperlinks to see examples of their use in the original contexts.

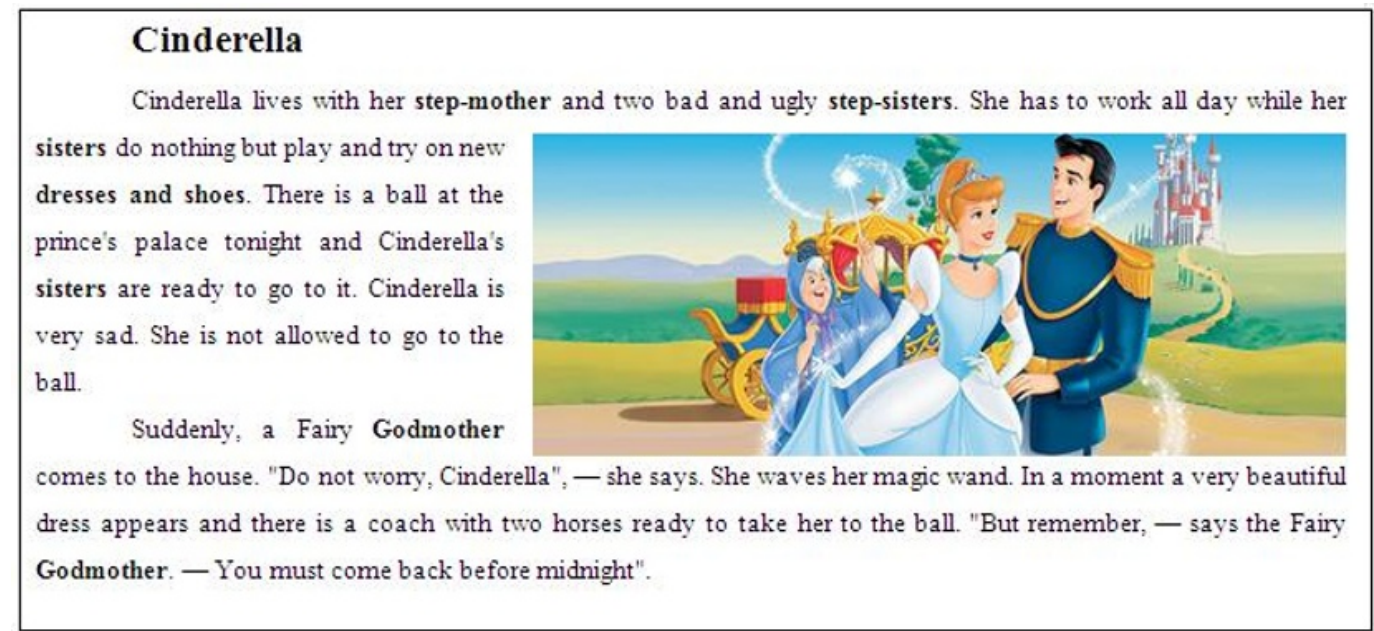

Fig.5. Fragment of the fairy tale "Cinderella" (using an electronic dictionary with hyperlinks to the context).

\section{Results and Discussions}

In order to confirm our hypothesis, we conducted an experiment in combination with such research methods as observation, questioning and testing. During the experimental work, the students of the first group (control group) in the number of 14 people were offered to study and use vocabulary in the speech on the topics mentioned above, based on the traditional method without the use of ICT. Students of the second group (experimental) in the 
amount of 14 people performed exercises on the same topics using the capabilities of the computer and ICT.

Approbation of these methods in the framework of the experiment in the primary school allowed one to estimate adequately and objectively a compliance with the declared requirements.

At the final stage of the experimental work, the control works and interactive testing for both groups of students were carried out as a summary of the results. The results of the experiment showed that the quality of knowledge of the students in the control group for all subjects is lower by approximately $30 \%$ compared to the experimental group (Fig. 6).

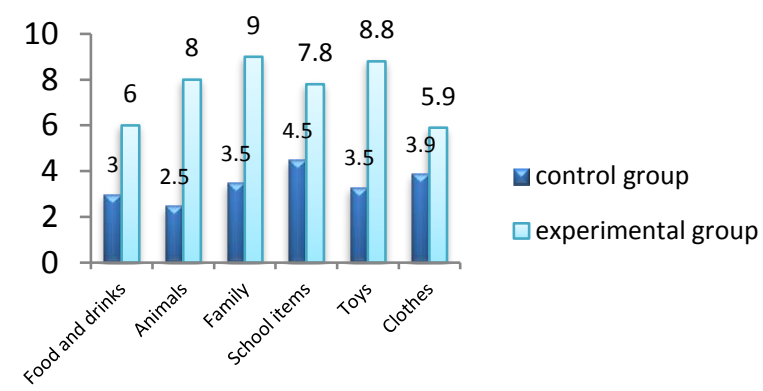

Fig.6. Average indicators of completed control tasks among students in the control and experimental groups.

As a result of the implementation of the method developed by us, excellent indicators of final work and testing were obtained. Thus, our statistical analysis of the data shows a positive dynamics of the experimental group at the end of the experiment in comparison with the control group. That allows drawing a conclusion about the success of the experiment.

\section{Conclusion}

Taking into consideration many aspects of the formation of lexical skills of junior schoolchildren in English classes by means of the modern ICT tools and the results of the experiment, it can be stated that its goal was achieved.

Thus, in a foreign language class with the help of a computer, a number of didactic tasks can be solved: to replenish the vocabulary, to form a stable motivation for learning a foreign language, to provide individualization and differentiation of instruction, to take into account the abilities of children, their level of training.

In this work we established and experimentally confirmed the significance and effectiveness of the introduction and use of computer technologies in the process of teaching English at the initial stage. In particular, the process of a junior schoolchild's lexical skills formation is faster and more efficient with the help of computer and computer programs.

Thus, the complex realization of the possibilities of modern ICT tools in the school education system in the initial classes allows one to model a highly developed global information and communication environment, and in the aspect of language communication, a linguistic and socio-cultural information and communication environment in which the secondary linguistic personality is socialized.

\section{References}

1. E. G Azimov, A. N. Shchukin, A new dictionary of methodological terms and concepts (theory and practice of teaching languages) (Moscow: Ikar, 2009)

2. N. D. Gal'skova, Modern methods of teaching foreign languages. Teacher's Guide (M.: Arcti, 2003)

3. N. D. Gal'skova, N. I Gez, Theory of teaching foreign languages. Linguodidactics and methodology. Textbook (M.: Academy, 2006)

4. Y. A Pirverdieva, Infocommunication technologies in science, production and education: a collection of scientific papers of the sixth international scientific and technical conference INFOCOM 6. Part 3. (Stavropol: North-Caucasian Federal University, 2014)

5. Y. A. Pirverdieva, Mathematical Methods and Information Technologies in Economics, Sociology and Education: Materials of the XXXI International Scientific and Technical Conference (Penza: Izd-vo Privolzhsky House of Knowledge, 2013)

6. Yu. L. Tikhomirova, Modern Information Technologies in the Process of Forming Lexical Skills in English Lessons. Festival of Educational Ideas-(2015)

7. V. A. Silakov, I. A. Krylova, The Scientific and Methodical Electronic Journal "Concept" 11, 916$920(2016)$

8. L. A Tsvetkova, Foreign languages in school 2, 4347 (2002)

9. A. N. Shatalov, M. V. Nikireeva, Regional Education: Modern Trends 1(31) 76-80 2017

10. Children's site with fairy tales in English Fun4child.ru URL: http://www.fun4child.ru/4detskijj-sajit.html (date of circulation: 03/05/2018).

11. E. V. Solopova Dissertation: Formation of the communicative competence of younger schoolchildren speaking another language with computer application in the process of education URL:http://www.dissercat.com/content/formirovani e-inoyazychnoi-kommunikativnoi-kompetentsiimladshikh-shkolnikov-s-primeneniem-ko (date of circulation: 02/05/2018). 